\title{
Feeling and showing: A new conceptualization of dispositional teacher enthusiasm and its relation to students' interest
}

\author{
Melanie M. Keller ${ }^{\mathrm{a}, \mathrm{b}, *}$, Thomas Goetz ${ }^{\mathrm{a}, \mathrm{b}}$, Eva S. Becker ${ }^{\mathrm{a}} \mathrm{b}$, Vinzenz Morger ${ }^{\mathrm{b}}$, \\ Lauren Hensley ${ }^{\mathrm{c}}$ \\ ${ }^{a}$ Empirical Educational Research, University of Konstanz, Germany \\ ${ }^{\mathrm{b}}$ Thurgau University of Teacher Education, Switzerland \\ ${ }^{\mathrm{c}}$ Dennis Learning Center, The Ohio State University, Columbus, OH, USA
}

Keywords:

Teacher enthusiasm

Enjoyment

Emotional expressivity

Student interest

Multilevel structural equation modeling

\begin{abstract}
A B S T R A C T
Although teacher enthusiasm is a relevant variable in the teaching context, a clear definition is still lacking. Research on teacher enthusiasm is characterized by ambiguous conceptualizations of enthu siasm as either an affective characteristic of teachers or behaviors of expressiveness. Integrating these two notions, a new conceptualization of dispositional teacher enthusiasm, defined by teachers' positive affect and positive emotional expressivity, was developed. It was hypothesized that dispositional teacher enthusiasm would relate to students' interest, mediated by students' perceived teacher enthusiasm. Based on a correlational study design, secondary teachers $(N=75)$ from Switzerland reported on their enthusiasm, complemented by student ratings $(N=1523)$ on perceived enthusiasm and interest. Multilevel structural equation modeling revealed that dispositional teacher enthusiasm positively pre dicted students' interest, which was fully mediated by students' perceived enthusiasm, providing the basis of a valid definition of teacher enthusiasm. Based on this integrative definition, implications for future research are discussed.
\end{abstract}

\section{Introduction}

Act enthusiastic and you will be enthusiastic. (Dale Carnegie, 1888-1955)

When reviewing the educational literature, talking with stu dent-teachers about what makes a good teacher, or reminiscing about teachers in one's own schooling experiences, encountering the term "enthusiasm" is almost inevitable. The term usually is applied to those teachers who had a certain, contagious fire in them, who burned for their subject and transmitted interest, cu riosity and joy for learning and subject related tasks. In educational research, teacher enthusiasm as a topic of scientific scrutiny emerged during the 1960s. Since then, it has been suggested that teacher enthusiasm is a key element of effective, high quality teaching (e.g., Brophy \& Good, 1986), a desirable characteristic of good teachers (e.g., Feldman, 2007), and an essential ingredient of supportive classrooms (e.g., Kunter et al., 2008).

\footnotetext{
* Corresponding author. Empirical Educational Research, University of Konstanz, Universitaetsstrasse 10, D-78457 Konstanz, Germany. Tel.: +49 (0)7531 882336.

E-mail address: melanie.keller@uni-konstanz.de (M.M. Keller).
}

This widely agreed on importance of teacher enthusiasm might stem from its ability to positively impact students' progress and learning. Studies with experimental or repeated measures designs have shown that a variety of student outcomes seem to benefit from teacher enthusiasm. For instance, scholars have demonstrated that students' cognitive learning (e.g., achievement; Kunter et al., 2013; see also Keller, Neumann, \& Fischer, 2013) is positively influenced by teacher enthusiasm. Other positive outcomes include motivational (e.g., intrinsic motivation; Patrick, Hisley, \& Kempler, 2000), affective (e.g., enjoyment; Frenzel, Goetz, Lüdtke, Pekrun, \& Sutton, 2009), and behavioral characteristics (e.g., attention; Bettencourt, Gillett, Gall, \& Hull, 1983). Synthesizing the results of these studies, it can be hypothesized that teacher enthusiasm first and foremost is associated with students' motivational and affec tive outcomes (e.g., enjoyment, interest), whereas achievement is indirectly related to enthusiasm, mediated by students' motivation or attention during class (see also Allen, Witt, \& Wheeless, 2006).

Of all the student outcomes related to teacher enthusiasm, students' interest is of particular importance. As a combination of intrinsic value and enjoyment (e.g., Krapp, 2007), interest is likely to benefit from teacher enthusiasm based on two central mechanisms - value induction and emotional contagion. These 
mechanisms explain how teacher enthusiasm exerts influence on students' outcomes (see for example, Keller et al., 2013). In both mechanisms, enthusiastic teachers provide cues during the act of teaching that allow students to deduce the teacher's personal value and enjoyment. Students consequently experience value and enjoyment themselves, reflective of elevated levels of interest. Drawing on theories of academic interest (e.g., Hidi \& Renninger, 2006), it can be hypothesized that students' perceptions of teach ers' enthusiasm provide the environmental trigger that results in students' initial situational interest. When students adopt the personal value exemplified by the enthusiastic teacher, situational interest can be transformed into individual interest. Given these likely pathways, the present study investigates the role of teacher enthusiasm in student interest.

Existing research supports the argument that teacher enthu siasm is important (Brophy \& Good, 1986; Kunter et al., 2013), though the notion of what teacher enthusiasm is has varied considerably. Much of this uncertainty is due to the fact that teacher enthusiasm has been investigated in educational research over a number of decades and by researchers with different backgrounds (education, educational psychology, etc.). To clearly speak about teacher enthusiasm as an important characteristic of teachers and supportive classroom environments, we need to be able to clearly define what we mean by teacher enthusiasm. Starting with the term itself, the Oxford English Dictionary de scribes enthusiasm as "intense and eager enjoyment, interest, or approval" (Stevenson \& Waite, 2011). In research, teacher enthu siasm has been described as a teacher's positive affective experi ences when engaged with teaching (Kunter, Frenzel, Nagy, Baumert, \& Pekrun, 2011; Kunter et al., 2008). Enthusiastic teach ing also is connected to behaviors of expressiveness (see Keller et al., 2013) that denote the teacher's liking and positive affect connected to the subject and teaching itself. On the one hand, teacher enthusiasm can be considered as a dispositional charac teristic of teachers and described as a form of strong, positive af fective connection a teacher feels toward teaching and his/her subject. On the other hand, teacher enthusiasm can be considered as a set of demonstrated behaviors in a classroom related to the positive affective experience. A gap in the literature exists in that no known studies have brought together these two notions of teacher enthusiasm. More precisely, it is not clear whether teacher enthusiasm as an affective characteristic is sufficient in precipi tating behaviors of enthusiasm. It is the aim of the present study to clarify these aspects by conceptualizing a new form of disposi tional teacher enthusiasm and investigating its relation to behav iorally shown teacher enthusiasm, as perceived by students, as well as students' interest.

\subsection{Teacher enthusiasm: its conceptualization}

\subsubsection{Teacher enthusiasm as instructional behavior}

In the educational research literature, teacher enthusiasm most often has been conceptualized as an instructional behavior (e.g., Brophy \& Good, 1986). Enthusiastic teaching has from the beginning been considered in terms of expressiveness. Rosenshine (1970) called it animated teaching and summarized research that described enthusiastic teaching as buoyant, lively, or the opposite of dull. Collins (1978) devised indicators for enthusiastic teaching including use of gestures or lively facial expression. In a post hoc study, Murray (1983; see also 2007) identified additional indicators, such as display of interest or humor. Other researchers (e.g., Bettencourt et al., 1983; Patrick et al., 2000) have employed these (mostly nonverbal) behaviors of expressiveness in their conceptualizations of enthusiastic teaching. Altogether, research evidence based on the conceptualization of teacher enthusiasm as an instructional behavior points toward associated behaviors that are largely, if not exclusively, behaviors of expressiveness that denote a teacher's passion and enjoyment.

\subsubsection{Teacher enthusiasm as a personality trait}

As Kunter et al. (2008) point out, the behavioral conceptuali zation, which stays purely on the surface level, is not suitable in explaining the internal processes of teachers. According to Kunter et al., teacher enthusiasm can also - but, as we argue, not neces sarily contrarily - be conceptualized as a trait like characteristic of teachers. As an affective component of teacher motivation, enthu siasm refers to a teacher's positive affective experience (e.g., enjoyment, pleasure and excitement) while teaching. In this way, enthusiasm can be regarded as a "trait like, habitual, recurring emotion" (Kunter et al., 2008, p. 470). Kunter et al. distinguished between a teaching related and a content related dimension of this trait like enthusiasm. The teaching dimension, in particular, was found to be highly predictive of motivationally supportive instructional behaviors such as autonomy, social support, and monitoring. Trait like enthusiasm corresponds to high quality teaching and impacts student outcomes (e.g., enjoyment; Kunter et al., 2013). What remains to be shown, however, is whether such variables also relate to the behaviors of expressiveness conceptualized as enthusiastic teaching in prior research.

Frenzel et al. (2009) have contributed to what is known about teacher enthusiasm as a trait. They assessed teachers' enthusiastic teaching by means of students' perceptions on a global, high inference scale. Enthusiastic teaching was positively related to teachers' self reported enjoyment in the teaching context. Although Frenzel et al. (2009) did not denote teacher enjoyment as enthusiasm, their operationalization of enjoyment reflects a construct fairly similar, if not identical, to Kunter et al. (2008)'s construct of enthusiasm (see also Kunter et al., 2011). In contrast to enthusiastic teaching as a behavior, teacher enthusiasm as a personality trait can be defined as a tendency to experience positive affect during teaching.

In summary, there are two different, if overlapping and interdependent, notions of teacher enthusiasm present in the educational literature: (1) teacher enthusiasm as an instructional behavior, mostly nonverbal behaviors of expressiveness, and (2) teacher enthusiasm as a positive affective trait of teachers, denoting enjoyment and pleasure during teaching. To what extent these conceptions overlap, and whether and how they may be integrated into an overarching concept of teacher enthusiasm, still remain to be shown. In the present study, we integrate the two positions in order to consider both emotional expressivity and positive affect as constituents of dispositional teacher enthusiasm.

\subsubsection{The role of emotional expressivity in teacher enthusiasm}

Emotional expressivity can be defined as "individual differences in the extent to which people outwardly display their emotions" (Kring, Smith, \& Neale, 1994, p. 934). Although different facets of emotional expressivity have been postulated and are empirically supported, the different approaches share the notion of positive and negative emotional expressivity as two distinct sub facets of emotional expressivity (Gross \& John, 1998; King \& Emmons, 1990; Kring et al., 1994). Positive emotional expressivity denotes the tendency to express positive emotions (e.g., enjoyment, pride). Conversely, negative emotional expressivity denotes the tendency to express negative emotions (e.g., anxiety, anger). As teacher enthusiasm has been conceptualized as a form of positive affect, we will only consider positive emotional expressivity of teachers for the purposes of this study. 


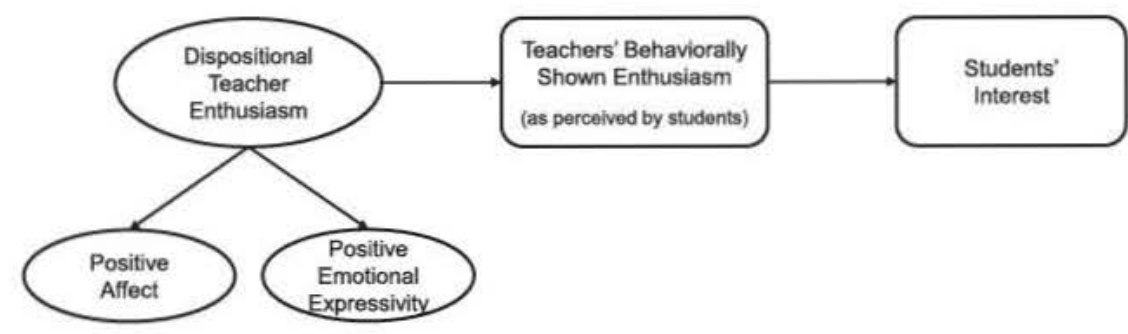

Fig. 1. Research model for dispositional teacher enthusiasm (indicated by teachers' positive affect and positive emotional expressivity) influencing students' interest, mediated by behaviorally shown enthusiasm, as perceived by students.

From a theoretical perspective, three aspects of emotions are interlinked: emotion experience, emotional expressivity (the dispositional characteristic denoting a person's tendency to express emotions; Gross, John, \& Richards, 2000), and emotional expres siveness (the observable behaviors of expressiveness; Gross \& John, 1997, 1998). Emotional expressivity regulates the extent to which emotion experiences find their outwardly observable emotional responses in the form of expressive behaviors (see Gross et al., 2000). Empirical evidence supports that emotionally expressive behaviors (e.g., facial expression, physiological responses) are associated with both emotion experience (Gross et al., 2000; Rosenberg \& Ekman, 1994) and the trait of emotional expressivity (Gross et al., 2000; King \& Emmons, 1990; Kring et al., 1994). Summarizing the relations in terms of positive emotions, more intense experiences of positive emotions result in higher levels of emotion expressive behaviors; simultaneously, persons scoring high on emotional expressivity have generally elevated levels of emotion expressive behaviors when compared to low expressivity individuals (see Gross et al., 2000).

Regarding teachers, emotions have been the focus of several investigations starting about 10 years ago (e.g., Sutton \& Wheatley, 2003). Since then, teacher emotion research has focused on the emotion experience of teachers in their professional activities, with an emphasis on actual teaching activity in classrooms. Although research on the effects of teachers' emotion experiences are rare, evidence suggests that positive teacher emotions like enjoyment accompany high quality teaching and favorable student outcomes. For instance, Frenzel et al. (2009) found that teachers' enjoyment (perceived by students as enthusiastic teaching behaviors) related to students' own enjoyment during class.

Beyond teacher enthusiasm, research on teachers' positive emotion expression focuses on (1) teacher immediacy, and (2) teacher expressiveness. Teacher immediacy refers to nonverbal behaviors that denote physical and psychological closeness be tween teachers and students (see, for example, Allen et al., 2006). ${ }^{1}$ Immediacy has been connected to students' learning outcomes (e.g., motivation, achievement). Teachers' emotional expressive ness primarily has been investigated in the setting of college teaching. In these studies, teacher expressiveness is defined as enthusiasm and humor (e.g., Ware \& Williams, 1975) and is closely related to enthusiastic teaching as defined by Collins (1978) or Murray (2007). As with investigations of enthusiastic teaching. teacher expressiveness has been investigated from a behavioral perspective, relying on student ratings of teachers' displayed expressive behaviors. In existing research, the concept of teacher expressiveness is rarely connected to teacher emotions or defined in terms of an emotion expression component of experiences.

\footnotetext{
${ }^{1}$ At present, the concept of teacher immediacy is not very well integrated into educational psychological research; however, the operationalization of the nonverbal behaviors associated with immediacy are very similar to those of enthusiastic teaching (see Babad, 2005, 2007).
}

Based on what we know about emotion experience and emotional expressivity, enthusiastic teaching can be viewed in terms of the behavioral expression of enjoyment (see also Frenzel et al., 2009). It is the aim of the current study to bring together two ap proaches to understanding teacher enthusiasm: (1) the experiential component of a dispositional teacher enthusiasm, that is, the experience of enjoyment during teaching (e.g., Kunter et al., 2008), and (2) positive emotional expressivity of teachers (Gross \& John, 1998). Our purpose is to investigate these aspects' joint contribu tion to behaviorally shown teacher enthusiasm, as perceived by students.

\section{Model for dispositional teacher enthusiasm}

We devised a model for dispositional teacher enthusiasm that brings together affective teacher characteristics and behaviors of expressiveness (see Fig. 1). Dispositional teacher enthusiasm in cludes an experiential component denoting teachers' positive affect or positive emotion experiences during teaching. Dispositional enthusiasm also draws from the behavioral notion of teacher enthusiasm in existing research through the inclusion of positive emotional expressivity, denoting the tendency to express positive emotions while teaching.

These two components - positive affect and positive emotional expressivity - define dispositional teacher enthusiasm as a latent construct. As depicted in Fig. 1, we assume that dispositional teacher enthusiasm manifests itself in class during teaching in such a way that students can observe it and become aware of it, thus informing their perception of the teacher's enthusiasm. Through this behavioral element, operationalized via students' perceptions on a class level, we also hypothesize that dispositional teacher enthusiasm relates to students' interest.

\section{The present study}

The present study aimed to establish our conceptualization of dispositional teacher enthusiasm as depicted in Fig. 1, validate it with regard to students' perceived teacher enthusiasm, and investigate its relation to students' interest.

We addressed the ambiguous nature of enthusiasm and merged its two prevalent conceptualizations as positive affect and expressivity into one construct: dispositional teacher enthusiasm. Validating the new conceptualization of teacher enthusiasm was one central element of the present study. We ascertained the validity of this new dispositional construct by relating it to stu dents' perceptions of their teachers' enthusiasm. We hypothe sized that dispositional teacher enthusiasm would positively relate to students' perceptions of teacher enthusiasm. Having both teachers' and students' perspectives on teacher enthusiasm enabled us to develop a balanced definition of enthusiasm and investigate its role during teaching and relations to student outcomes. 
The relation to students' interest was the second central element of the study: we hypothesized that dispositional teacher enthusiasm would be associated with students' interest, mediated by students' perceived teacher enthusiasm. Previous research has shown that teacher enthusiasm primarily relates to students' af fective and motivational outcomes (Frenzel et al., 2009; Patrick et al., 2000). In the present study, we focused on an important correlate of teacher enthusiasm-students' interest-which can be regarded as both a motivational and an affective variable (Ainley, 2006).

In summary, the present study introduced dispositional teacher enthusiasm as a new integrative construct and investigated how two perspectives on teacher enthusiasm-teachers' and students'related to students' interest. Our study aimed to (1) validate the new construct of dispositional teacher enthusiasm, and (2) inves tigate its relation to students' interest.

\subsection{Hypotheses}

Based on the research model presented in Fig. 1, we considered three research hypotheses.

\subsubsection{Hypothesis 1}

The conceptualization of dispositional teacher enthusiasm would be reasonable. Specifically, the assumptions of its mea surement model would be statistically supported (H1a) and dispositional enthusiasm would positively relate to students' perceived teacher enthusiasm (convergent construct validity; $\mathrm{H} 1 \mathrm{~b}$ ).

Hypothesis 1a was tested via confirmatory factor analysis; we sought an adequate model fit as indicated by commonly used model fit indices (RMSEA, CFI, and TLI; see Hu \& Bentler, 1999). Regarding hypothesis $1 \mathrm{~b}$, we postulated that dispositional teacher enthusiasm would positively predict students' perceived teacher enthusiasm (moderate to strong effect as denoted by explained variance in students' perceived teacher enthusiasm).

\subsubsection{Hypothesis 2}

Dispositional teacher enthusiasm would positively relate to students' interest.

Based on prior research showing evidence of teacher enthusi asm's relations to students' motivational and affective outcomes, we hypothesized that dispositional teacher enthusiasm would relate positively to students' interest, consisting of value and enjoyment components (Krapp, 2007).

\subsubsection{Hypothesis 3}

The inferential effect of dispositional enthusiasm on students' interest would be mediated by students' perceived teacher enthusiasm.

The final hypothesis involved testing our complete research model. Specifically, we investigated the extent to which disposi tional teacher enthusiasm related to students' perceived teacher enthusiasm and the extent to which this perception, in turn, related to students' interest. We hypothesized a mediation effect for perceived teacher enthusiasm (see Frenzel et al., 2009).

\section{Methods}

The data for the present study were part of the first wave of a larger, longitudinal study on students' emotion experiences in the German speaking part of Switzerland. In the current study, we conducted survey research at eight Swiss schools in four subjects: German, English, French, and mathematics. All students were ninth graders in the high achieving track of the Swiss secondary school system, known as Gymnasium.

\subsection{Sample E data structure}

Seventy five teachers agreed to participate in the research study and represented the four subjects to a fairly equal amount ( $\begin{array}{ll}n & 20 /\end{array}$ 20/19/16 for German, English, French, and mathematics, respec tively). We utilized 1523 student ratings of teachers, provided by 863 students (56.5\% female; $M_{\text {age }} 14.93$ years, SD 0.68 years; two students did not indicate their age). ${ }^{2}$ Teachers, whose average age was 46.06 years (SD 10.59 years; Minimum 28 years, Maximum 64 years), had been teaching for an average of 16.14 years ( $S D$ 10.64). Forty three teachers were female and 27 were male, with the remaining five teachers not indicating their gender.

\subsection{Measures}

\subsubsection{Teachers' positive affect}

For this component of teacher enthusiasm, we made minor adaptions to Kunter et al.'s $(2008,2011)$ teacher enthusiasm scale. The scale assessed enjoyment and positive experiences related to teaching. The items appear in Appendix A; all items were rated with respect to teaching one subject in one specific class. The scale had three items that were rated on a five point scale from (1) agree not at all to (5) agree totally. The scale achieved acceptable internal consistency (Cronbach's $\alpha \quad .76)$ and was slightly, yet not signifi cantly, negatively skewed.

\subsubsection{Teachers' emotional expressivity}

The second component of teacher enthusiasm-positive emotional expressivity-denotes a teacher's tendency to show positive emotions while teaching. We adapted Gross and John's (1998; German translation by Mohiyeddini, John, \& Gross, 2008) expressivity scale for use in the teaching context. The resulting scale included eight items, which appear in Appendix A. A sample item was, "When I'm happy in class, my feelings show." The items were rated on a seven point scale with the anchors (1) agree not at all, (4) neutral, and (7) agree totally. The scale had good internal consistency (Cronbach's $\alpha \quad .83$ ) and was slightly, yet not signifi cantly, positively skewed.

\footnotetext{
${ }^{2}$ Altogether, $N \quad 863$ students from $N \quad 43$ classes participated. All students answered all items (on their interest and perceived teacher enthusiasm) with respect to the four subjects, which resulted in student data from $172(43 \times 4)$ classes. For these classes, the respective teachers were asked to voluntarily participate in the study, and 75 of them did. Although there could have been up to 172 teachers for our participating 43 classes, it also could have been the case that a given teacher taught more than one subject. The possible total number of different teachers is unknown to us, yet regarding our sample used for the present analyses, all of the 75 teachers only appear one time.For these teachers, we utilized the respective student ratings $\left(N_{1} \quad 1523\right)$; thus, on average students rated 1.94 teachers. For analysis purposes, we clustered student ratings ( $N_{1} \quad 1523$, level 1) into teachers $\left(N_{2} \quad 75\right.$, level 2) to allow us to investigate effects of teachers on student variables. Due to this data structure, we have students appearing up to three times (with their ratings on the different subjects and teachers, respectively) in our sample. To check whether we made any significant error in our estimations by ignoring the nesting of student ratings in students, we calculated the design effect (DEFF) for both student-assessed variables. This figure indicates to what extent the standard errors are underestimated when ignoring the nesting of subject measures in persons, and should be less than two (see Maas \& Hox, 2005). Our analyses yielded design effects below two (perceived enthusiasm: DEFF 1.12 interest: DEFF 1.00). Thus, we can assume that our estimation results yielded for the data structure described above are not biased in any substantial way.To further check the validity of our results, we randomly selected one rating per student and ran our analyses (related to hypotheses $1 \mathrm{~b}, 2$, and 3 ) with a reduced sample of $N 863$ student ratings and their respective teachers. The results were similar to those reported on the overall student rating/teacher sample. Regarding hypotheses $1 \mathrm{~b}$ and 2 , the changes in regression coefficients $\beta$ were -.13 and .01 , respectively (changes in $R^{2}$ were -.17 and .02 , respectively). For the overall model, the results including model fit were very similar. The indirect effect was somewhat smaller (change in $\beta$ was -.08 ).
} 


\subsubsection{Students' perceived teacher enthusiasm}

Our measure of perceived teacher enthusiasm was based on Marsh and Bailey (1993)'s scale. A sample item was "Our teacher in SUBJECT teaches with enthusiasm." The scale included three items that were rated from (1) agree not at all to (5) agree totally. The scale achieved good reliability (Cronbach's $\alpha$.85) and was significantly negatively skewed, that is, students tended to agree with the items above the mean of the rating scale. The intraclass correlation (ICC) reflects the proportion of between cluster variance to total variance (see for example, Lüdtke, Trautwein, Kunter, \& Baumert, 2006). For perceived teacher enthusiasm, the ICC of .43 indicated that a rela tively high amount (about 43 percent) of the total variance was between classes.

\subsubsection{Students' interest}

According to Krapp (e.g., 2007), academic interest reflects stu dents' enjoyment when engaging in subject related tasks (affective component) and the personal value and importance of the subject (value component). Students' level of interest was measured with four items. One item measured the affective component in the form of students' enjoyment (Nett, Goetz, \& Hall, 2011). For the value component, three items assessed intrinsic value (Goetz, Pekrun, Hall, \& Haag, 2006). The items appear in Appendix A. The four items were rated on a five point scale from (1) agree not at all to (5) agree totally. The scale was significantly negatively skewed, with students agreeing to the items above the mean of the rating scale. The overall scale achieved good reliability (Cronbach's $\alpha$.84), with about 28 percent of the total variance occurring between classes.

\subsection{Hierarchically structured data analysis}

Our sample represented a clustered data structure with students on level $1\left(\begin{array}{ll}N_{1} & 1523\end{array}\right)$ clustered within teachers on level 2 $\left(\begin{array}{ll}N_{2} & 75\end{array}\right)$. The mean cluster size was 20.41 students. We conducted multilevel structural equation modeling using the software Mplus 7.0 (Muthén \& Muthén, 1998-2012). Multilevel structural equation modeling takes into account the nested data structure, thus avoiding estimation problems. It also allows for the consideration of latent variables, such as dispositional teacher enthusiasm (see also Parker, Marsh, Lüdtke, \& Trautwein, 2013).

The model as depicted in Fig. 1 includes two different types of latency (see Marsh et al., 2012). Teachers' positive affect and posi tive emotional expressivity are latent in terms of correcting for measurement error, whereas students' perceived teacher enthu siasm and interest (included as scale means on the student level) are latent in terms of correcting for sampling error.

The models were estimated using the maximum likelihood parameter estimation in Mplus with robust standard errors. For further information, a sample Mplus input file regarding the ana lyses and model specifications appears in Appendix B.

\section{Results}

\subsection{Descriptive results}

The descriptive statistics and zero order intercorrelations of our study variables are shown in Table 1 . Overall, teachers reported high levels of positive affective experiences with respect to teach ing. For the tendency to express their positive experiences in class through nonverbal displays, teachers were slightly above neutral (four on the seven point scale). Students perceived their teachers to be highly enthusiastic and reported moderate to high levels of in terest. The correlations of study variables were all statistically sig nificant. Students' interest was moderately related to students'
Table 1

Descriptive statistics and intercorrelations of study measures.

\begin{tabular}{|c|c|c|c|c|c|c|c|}
\hline & $M$ & $S D$ & Skewness $(S E)$ & (1) & $(2)$ & (3) & (4) \\
\hline \multicolumn{8}{|l|}{ Teacher } \\
\hline (1) Affective component & 4.34 & 0.51 & $-0.51(.28)$ & 1 & $.35^{* * * *}$ & $.36^{* * *}$ & $.34^{* *}$ \\
\hline $\begin{array}{l}\text { (2) Positive emotional } \\
\text { expressivity }\end{array}$ & 4.57 & 0.91 & $0.36(.29)$ & & 1 & $.50^{* * *}$ & $.30^{* *}$ \\
\hline \multicolumn{8}{|l|}{ Student } \\
\hline $\begin{array}{l}\text { (3) Perceived teacher } \\
\text { enthusiasm }\end{array}$ & 3.91 & 0.89 & $-0.84(.06)$ & & & 1 & $.73^{* * *}$ \\
\hline (4) Interest & 3.15 & 0.51 & $-0.23(.06)$ & & & $.30^{* * *}$ & 1 \\
\hline
\end{tabular}

Note. Correlations are shown based on manifest variables; means across the respective items for each scale were calculated and then correlated to each other. Below the diagonal, correlations for the within-level are shown. Above the diagonal, correlations for the between-level are shown. ${ }^{* *} p<.01,{ }^{* * *} p<.001$.

perceived teacher enthusiasm, as well as to teachers' self reports of positive affect and positive emotional expressivity. Students' perceived teacher enthusiasm also had a moderately strong cor relation with teachers' self reports of positive affect and positive emotional expressivity.

\subsection{Hypothesis 1a: measurement model of dispositional teacher enthusiasm}

We used confirmatory factor analysis (CFA) to investigate whether dispositional teacher enthusiasm could be represented as a latent construct with positive affect and positive expressivity as its indicators. We fixed one additional parameter to overcome non identification of the second order factor by setting the variance of dispositional enthusiasm at value 1 . We compared this second order model with a unidimensional model where all items of positive affect and positive expressivity loaded on one factor; the results of model fit for both models is shown in Table 2. The second order model obtained a good absolute model fit, indicated by RMSEA, CFI, and TLI. It was also superior to the unidimensional model, given the second order model's lower AIC and BIC values. The resulting factor loadings for the second order model are shown in Fig. 2. Our results support the assumptions of the measurement model for dispositional teacher enthusiasm, and hypothesis 1a can be accepted.

\subsection{Hypothesis $1 b$ : convergent validity of dispositional teacher enthusiasm}

To establish and validate the conceptualization of dispositional teacher enthusiasm, we hypothesized that teachers' self reported dispositional enthusiasm would need to be reflected in such a way that students could perceive it. Thus, there should be a positive relation of dispositional teacher enthusiasm to students' perceived teacher enthusiasm.

To confirm this relation, we calculated a multilevel structural equation model with dispositional teacher enthusiasm as a second order latent variable, impacting students' perceived teacher enthusiasm. The model fit was good $\left(\begin{array}{llll}2 & 59.34, d f & 53, p & .26\end{array}\right.$ RMSEA .01, CFI .98, TLI 0.97). Dispositional teacher enthu siasm was positively related to perceived enthusiasm $(\beta \quad .76$,

Table 2

Fit indices for model comparison.

\begin{tabular}{llllllll}
\hline Model & $\chi^{2}$ & $d f$ & RMSEA & CFI & TLI & AIC & BIC \\
\hline Unidimensional model & 97.18 & 44 & .13 & .77 & 0.71 & 2128.99 & 2205.03 \\
Second-order model & 48.55 & 43 & .04 & .98 & 0.97 & 2082.36 & 2160.70 \\
\hline
\end{tabular}

Note. $N 74$. 


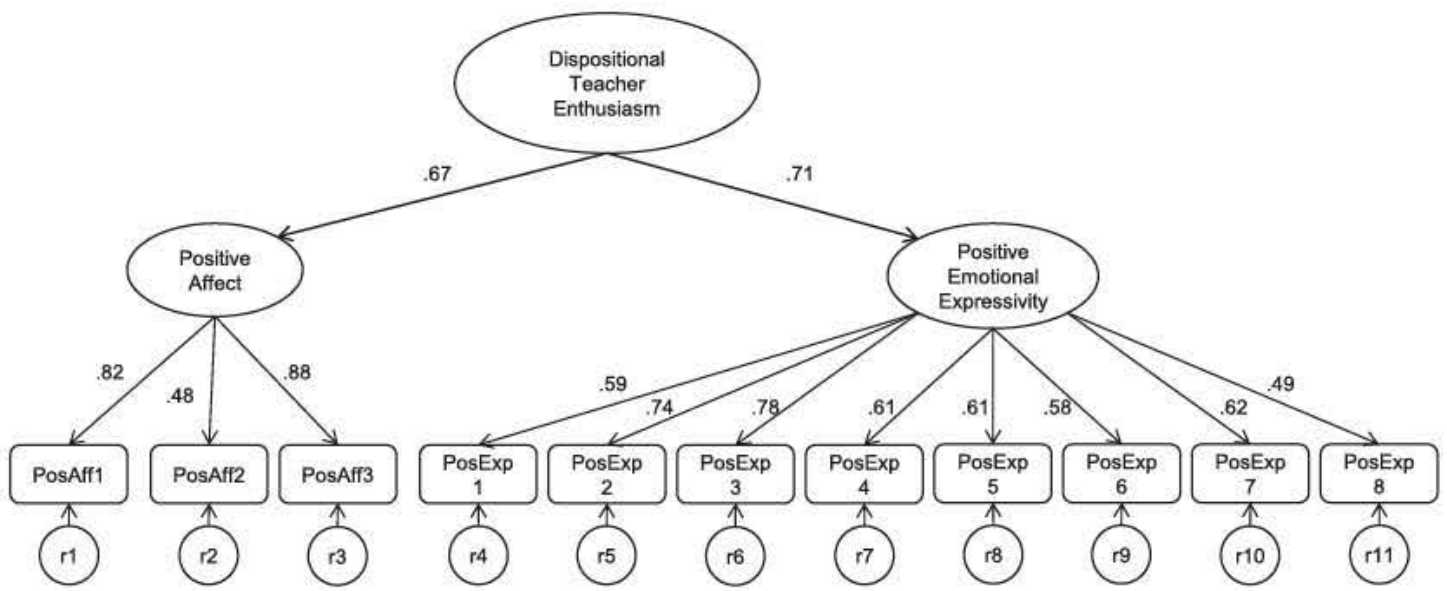

Fig. 2. Testing for the second-order model of dispositional teacher enthusiasm via confirmatory factor analysis (H1a). All factor loadings were highly significant ( $p<.001$ ). The sample size for teachers' self-report variables was $N \quad 74$.

$p<.001)$. The effect size of this relation was large, explaining about 58 percent of variance in students' perceived teacher enthusiasm. ${ }^{3}$

\subsection{Hypothesis 2: dispositional teacher enthusiasm influencing} students' interest

In our second hypothesis, we predicted that dispositional teacher enthusiasm would positively relate to students' interest. We calculated a multilevel structural equation model with the second order latent factor of dispositional teacher enthusiasm, described by its two latent indicators-positive affect and positive emotional expressivity-posited to influence students' interest on the between level.

Dispositional teacher enthusiasm significantly related to stu dents' interest $(\beta \quad .56, p<.001)$. The explained variance in stu dents' interest indicated a moderate effect $\left(\begin{array}{ll}R^{2} & \text {.31). The model }\end{array}\right.$ yielded a good fit $\left(\chi^{2} \quad 61.26, d f \quad 53, p \quad .20\right.$, RMSEA .01 , CFI .97, TU 0.96). Thus, hypothesis 2 can be supported.

5.5. Hypothesis 3: dispositional teacher enthusiasm influencing students' interest mediated by perceived teacher enthusiasm

Extending the second hypothesis, we predicted that the effect of dispositional enthusiasm on students' interest would be mediated by students' perceived teacher enthusiasm. We tested this hy pothesis by estimating a multilevel structural equation model; re sults for the between level are shown in Fig. 3. The model yielded good model fit $\left(\chi^{2} \quad 72.94, d f \quad 64, p \quad .21\right.$, RMSEA $\quad .01$, CFI $\quad .98$, TLI 0.98).

\footnotetext{
${ }^{3}$ At this point, we compared the effect of a second-order construct of dispositional enthusiasm with that of an alternative model including the two first-order latent factors of positive affect as predictors for students' perceived enthusiasm. Only positive expressivity significantly predicted students' perceived enthusiasm ( $\beta \quad 49, p<.001$ ). The effect of teachers' positive affect was rendered nonsignificant ( $\beta \quad .19, p \quad .15$ ), and about $36 \%$ of variance in students' perceived enthusiasm was explained. The absolute model fit for this alternative model was

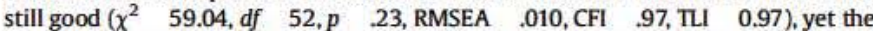
comparative fit indices, AIC and BIC, indicated that the second-order model was preferred (alternative model: AIC 5372.85, BIC 5580.66; second-order model: AIC 5371.28, BIC 5573.76). Together with the explained variance in students' perceived teacher enthusiasm, which was about $20 \%$ higher when including the second-order dispositional enthusiasm as predictor, it can be argued that a secondorder factor that weighs teachers' positive affect and positive expressivity is superior when considering dispositional teacher enthusiasm, as compared to two correlated first-order factors.
}

As can be seen in Fig. 3, dispositional enthusiasm significantly related to students' perceived teacher enthusiasm, which in turn related to students' interest. The effect of perceived enthusiasm on students' interest was large $\left(\begin{array}{ll}R^{2} & .49\end{array}\right)$. On the within level (not depicted in Fig. 3), students' perceived teacher enthusiasm had a small relation to students' interest $\left(\begin{array}{lll}\beta & .30, p<.001, R^{2} & .09\end{array}\right)$.

Our results further show full mediation for students' interest, with the direct path from dispositional enthusiasm to students' interest rendered non significant when students' perceived enthusiasm is accounted for in the model. The indirect effect via the mediator is significant and of a large size $\left(\beta_{\text {indirect }} .53\right.$, $p<.001)$.

\section{Discussion}

The central element of this paper was the new conceptualization of dispositional teacher enthusiasm, indicated by teachers' positive affect and positive emotional expressivity. This concept of dispo sitional enthusiasm was subjected to empirical scrutiny in testing three hypotheses. Bases on our analyses, we can support all three of them.

First, the validity of dispositional teacher enthusiasm was sup ported. More precisely, the measurement model (i.e., dispositional teacher enthusiasm as a second order latent construct defined by positive affect and positive emotional expressivity) was sound. In addition, convergent validation showed a strong positive relation to students' perceptions of teacher enthusiasm.

Second, we showed that dispositional teacher enthusiasm positively relates to students' interest, conceptualized as enjoy ment and intrinsic value. One likely interpretation is that enthusi astic teachers help instill in their students positive subject related affective experiences and a sense of the personal importance of the subject. Future research should examine whether this relation is causal in nature.

Third, our analyses confirmed that perceived teacher enthu siasm acts as a mediator between dispositional teacher enthu siasm and student' interest. We found a full mediation effect. Assuming temporal precedence, dispositional teacher enthusiasm can be said to influence students' perceptions. In turn, students' perceptions influence students' interest. Additional research should test the directionality of the relations suggested by this study. Prior research and the theoretical underpinnings of the model suggest causality, but the present study did not directly test causal relationships. 


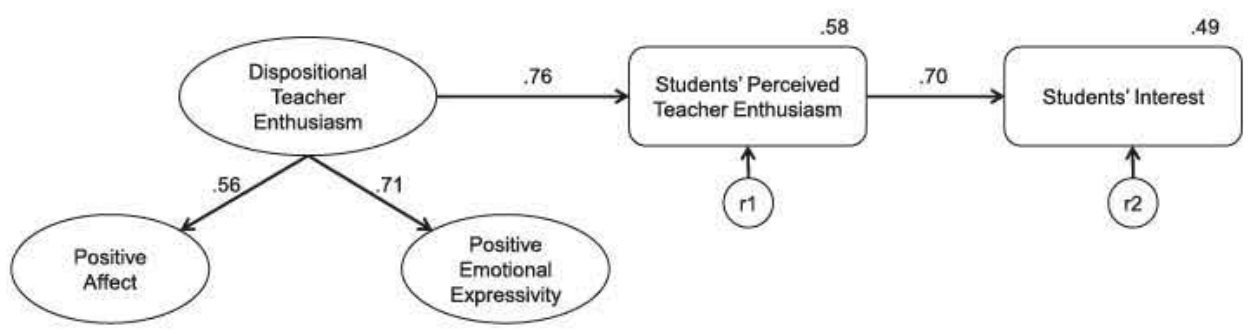

Fig. 3. Dispositional teacher enthusiasm influencing students' interest, mediated by students perceived teacher enthusiasm. To enhance clarity, the manifest indicators, loadings, and residuals for teachers' positive affect and positive expressivity are not displayed. Standardized path coefficients are shown, with all coefficients being highly significant

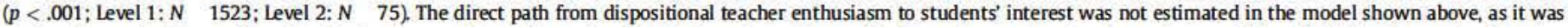
rendered non-significant after introducing the mediator of perceived enthusiasm into the model. The estimates for the dependent variables of students' perceived teacher enthusiasm and students' interest denote the respective explained variances on the between level $\left(R^{2}\right)$.

\subsection{Scholarly contributions}

Building upon earlier investigations of teacher enthusiasm, the present study is an important step forward. It provides a new conceptualization of dispositional teacher enthusiasm that integrates notions of teacher enthusiasm as positive affective experiences and nonverbal expressiveness during teaching. These two approaches are successfully combined into disposi tional teacher enthusiasm, which explains differences in teach ers' enjoyment and positive emotional expressivity during teaching.

This new conceptualization can be considered successful in sofar as it strongly relates to teachers' behaviorally shown enthusiasm as perceived by students. Thus, two perspectives on teacher enthusiasm - the teachers' and the students' - are combined in a coherent way. These perspectives provide two fundamental views on instructional processes in classrooms. As dispositional teacher enthusiasm in the present study was related to students' perceptions, this means we have identified an important teacher characteristic that influences instructional behavior. Dispositional enthusiasm as a personal, positive affec tive characteristic of teachers could also be important when it comes to teachers' professional and personal lives (e.g., engage ment, life satisfaction).

Furthermore, dispositional teacher enthusiasm is associated with students' interest, an important variable in the educational context. Not only can interest be regarded as a desirable outcome of teaching and learning processes, but more importantly it guides students' choices for their future careers. Beyond other influences (e.g., content or content dependent teaching factors), teacher enthusiasm is a relatively universal teaching strategy that can play an important role in forming students' interest.

Although future research should directly test causal pathways, it appears likely that dispositional teacher enthusiasm affects stu dents' perceptions and outcomes. That this effect on students' in terest is mediated by students' perceived teacher enthusiasm informs our understanding of the processes underlying the effects of dispositional teacher enthusiasm in two major ways. First, the mediation can be interpreted as dispositional teacher enthusiasm manifesting itself in specific teaching behaviors that can be observed by students and lead to their overall impression of teacher enthusiasm. Second, the existence of full mediation hints that teacher enthusiasm is only effective when it is actually perceived as such by the students.

Overall, this study provides a valid and integrative conceptual ization of dispositional teacher enthusiasm. By synthesizing the two major approaches in teacher enthusiasm research, the present study provides the basis for future investigations.

\section{Limitations}

Although the study was designed to overcome problems in previous research on teacher enthusiasm, there are also limitations. As with all cross sectional data sets, we essentially were examining inferential rather than causal effects. From a theoretical viewpoint, it is possible that there are reciprocal effects of student interest on teachers' enthusiasm. In her theoretical model, Frenzel (in press) creates an argument for students' motivation as one antecedent for teacher affect and emotions. In a qualitative interview study, Stenlund (1995) showed that students' learning behavior, growth, and motivation came together as a primary antecedent for teachers' enthusiasm. Furthermore, Kunter et al. (2011) found significant correlations between teacher enthusiasm and student character istics (enjoyment, achievement) and behavior (discipline), although their analyses were also based on cross sectional data. The process of figuratively infecting one another with emotions that is, emotional contagion - might naturally work in both di rections. There is evidence, however, that corroborates the effect of teacher enthusiasm on student outcomes (experimental studies; e.g., Patrick et al., 2000; longitudinal data by Frenzel et al., 2009; Kunter et al., 2013). As the aim of the present study was to intro duce and validate a new construct, longitudinal or large scale studies of dispositional teacher enthusiasm would be a natural next step.

From a statistical point of view, the final model was estimated on a manifest level for students' perceived teacher enthusiasm and interest. This approach enabled us to keep the estimates in proportion to the sample size; this meant, however, that the an alyses did not control for measurement errors on the students' side. Future studies may wish to control for such measurement errors.

The present study investigated the effects of teacher enthu siasm across four school subjects, thus taking the position that irrespective of domains, the effects of teacher enthusiasm are comparable. In so doing, we followed the common approach in teacher enthusiasm literature of combining results across domains (e.g., Collins, 1978; Murray, 1983; Patrick et al., 2000). However, we acknowledge that domain specific differences might play a role in teacher enthusiasm, as well. There is no known empirical support for enthusiasm's differential effects across domains, yet future research of this nature would elucidate our understanding of dispositional teacher enthusiasm.

Regarding domain specificity of dispositional teacher enthu siasm, Kunter et al. (2008, 2011) distinguished two facets: enthusiasm about the subject and enthusiasm about teaching. In the present study, only teachers' enthusiasm about teaching was 
considered, as it was the more powerful predictor of student outcomes in Kunter et al.'s studies. It might be possible that subject related facets of teacher enthusiasm are important for other student outcomes that have not yet been considered. Also, in conceptualizing dispositional teacher enthusiasm as a trait like characteristic, a certain temporal and trans situational sta bility is implied. Whether this assumption is justified cannot be answered on the basis of the present study. It remains possible that certain aspects of teachers' affect and emotional expressivity change from classroom to classroom or from day to day. A lon gitudinal study design including several assessment points per teacher would allow intra individual analyses to address this possibility.

\section{Conclusion}

Research on teacher enthusiasm to date is characterized by a lack of a clear definition of the construct. We brought together existing conceptualizations of expressiveness and positive teacher affect in an integrative concept of dispositional teacher enthusiasm. Based on this integrative conceptualization, effects and antecedents of teachers' enthusiasm can be systematically investigated in future research.

Of particular importance is the role of emotional expressiveness as observed by students, as this has been a focus in previous research that adopts a behavioral conceptualization of teacher enthusiasm. It will be interesting to learn whether teachers who report high levels of emotional expressivity are perceived as highly expressive in class, as well. Are all teachers who are enthusiastic (that is, who score high on dispositional enthusiasm) observed as such? If not, why? These questions suggest the likelihood of con ditional effects for the link between dispositional enthusiasm and perceived enthusiasm.

If we are to learn how to foster teachers' enthusiasm, re searchers need to know about its antecedents and the contexts in which it is able to unfold. Conversely, we need to understand those contexts in which enthusiasm is constrained and hindered. That enthusiastic teaching behaviors are trainable has already been shown (e.g., Patrick et al., 2000); however, criticism of enthusiasm training has also been offered (e.g., Babad, 2007). The present study indicates enthusiastic teaching behaviors stem from "internal processes" (Bettencourt et al., 1983, p. 448), that is, dispositional enthusiasm. In a sense, displaying enthusiastic teaching behaviors without actually experiencing enjoyment is similar to emotional labor or experiences of emotional dissonance (e.g., Morris \& Feldman, 1996), both of which have detrimental effects on health and well being (e.g., Bono \& Vey, 2005). Fostering enthusiastic teaching behaviors one sidedly bears the potential risk of further stress for teachers. Consequently, a next step in the research must be to investigate possible moderators of dispositional enthusiasm expressed during teaching, as well as possible contextual constraints. Only after that step can we safely consider the question of training and fostering of teacher enthusiasm.

\section{Acknowledgment}

This research was partially funded by the Swiss National Science Foundation [grant number 100014_131713/1]

\section{Appendix A. Item wording of scales.}

A1

Teachers' positive affect.

PosAff1 I teach SUBJECT in this class with great enthusiasm. (Ich unterrichte mit Begeisterung.)

PosAff2 I always enjoy having taught students new things. (Ich freue mich wirklich, wenn ich den Schülerinnen und Schülern etwas beigebracht habe.)

PosAff3 I really enjoy teaching SUBJECT in this class. (Mir macht das Unterrichten von FACH großen Spaß.)

A2

Teachers' positive emotional expressivity.

PosExp1 When I'm happy in class, my feelings show. (Wenn ich mich im Unterricht glücklich fühle, dann zeige ich es auch.) PosExp2 During teaching I laugh a lot. (Während des Unterrichts lache ich oft)

PosExp3 When I'm feeling well during teaching it's easy for me to go from being in a good mood to being really joyful.

(Wenn ich mich im Unterricht gut fühle, ist es leicht für mich, von einer guten in eine richtig freudige Stimmung zu kommen.)

PosExp4 I laugh out loud when my students tell me a joke that I think is funny (Wenn mir meine Schülerinnen und Schüler einen lustigen Witz erzählen, muss ich laut lachen.)

PosExp5 During teaching I often laugh so hard that my eyes water or my sides ache.

(Während des Unterrichts lache ich oft so, dass meine Augen tränen oder ich Seitenstechen bekomme.)

PosExp6 My happy moods in class are so strong that I feel like I'm "in heaven." (Meine glücklichen Stimmungen im Unterricht sind so stark, dass ich mich "wie im Himmel" fühle.)

PosExp7 In class my laugh is soft and subdued (R). (Im Unterricht ist mein Lachen sanft und gedämpft.)

PosExp8 Whenever I feel positive emotions during teaching, my students can easily see exactly what I am feeling. (Immer wenn ich mich während des Unterrichts gut fühle, können meine Schülerinnen und Schüler leicht erkennen, wie es mir geht.)

Note. (R) reverse coded.

Students' perceived teacher enthusiasm.

PercEnth01 Our teacher in SUBJECT teaches with enthusiasm. (Unser FACHlehrer unterrichtet mit Begeisterung.)

PercEnth02 Our teacher in SUBJECT enjoys teaching. (Unserem FACHlehrer scheint das Unterrichten großen Spaß zu machen.)

PercEnth03 Our teacher in SUBJECT tries to inspire students about the subject. (Unser FACHlehrer versucht im Unterricht, die Schüler vom Fach FACH zu begeistern.)

A4

Students' interest.

Affective component

Enj

In SUBJECT class, I usually enjoy myself.

(Im FACHunterricht freue ich mich in der Regel.)

Value component

IntrVal01

Whatever grade I get, SUBJECT is very important to me.

(FACH ist mir unabhängig von der Note sehr wichtig.)

IntrVal02 I find the subject SUBJECT very important.

(Ich halte das Fach FACH für sehr wichtig.)

IntrVal03 SUBJECT is my favorite subject.

(FACH ist mein Lieblingsfach.) 
Appendix B. Input syntax for Mplus testing hypothesis 3.

\author{
USEVARIABLES ARE \\ ent_m \\ PosAff1 PosAff2 PosAff3 PosAff4 \\ PosExp1 PosExp2 PosExp3 PosExp4 \\ PosExp5 PosExp6 PosExp7 PosExp8 \\ interest;

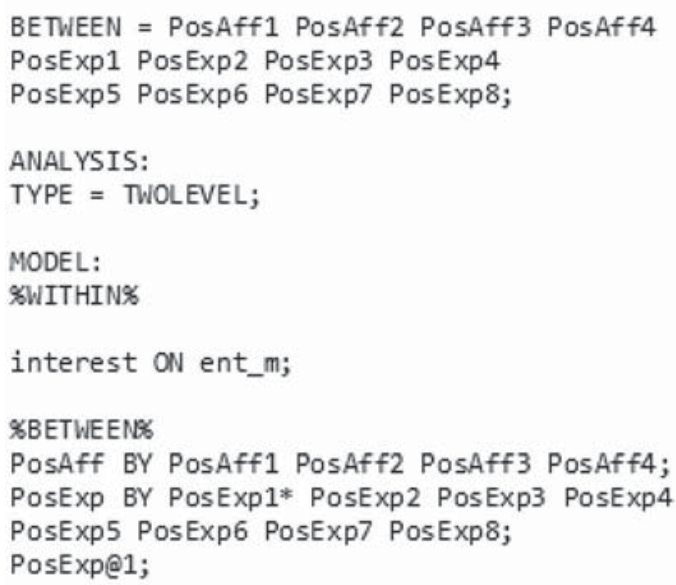

'Students' perceived teacher enthusiasm

(scale mean).

! Teachers' positive affect.

!Teachers' positive emotional

expressivity.

'Students' interest (scale mean).

\section{References}

Ainley, M. (2006). Connecting with learning: motivation, affect and cognition in interest processes. Educational Psychology Review, 18(4), 391 405. http:// dx.doi.org/10.1007/s10648-006-9033-0.

Allen, M., Witt, P. L., \& Wheeless, L. R. (2006). The role of teacher immediacy as a motivational factor in student learning using meta-analysis to test a causal model. Communication Education, 55(1), 2131.

Babad, E. (2005). Nonverbal behavior in education. In J. A. Harrigan, R. Rosenthal, \& K. R. Scherer (Eds.), The new handbook of methods in nonverbal behavior research (pp. 283 311). New York: Oxford University Press.

Babad, E. (2007). Teachers' nonverbal behavior and its effects on students. In R. P. Perry, \& J. C. Smart (Eds.), The scholarship of teaching and learning in higher education (pp. 201 261). Dordrecht: Springer.

Bettencourt, E. M., Gillett, M. H., Gall, M. D., \& Hull, R. E. (1983). Effects of teacher enthusiasm training on student on-task behavior and achievement. American Educational Research Journal, 20(3), 435450.

Bono, J. E., \& Vey, M. A. (2005). Toward understanding emotional management at work: a quantitative review of emotional labor research. In C. E. Härtel, W. J. Zerbe, \& N. M. Ashkanasy (Eds.), Emotions in organizational behavior (pp. 213 233). Mahwah, NJ: Lawrence Erlbaum Associates.
! Latent variable Positive Affect. ! Latent variable Positive Emotional Expressivity.

!Second order latent variable dispositional teacher enthusiasm.

!Effect of dispositional teacher enthusiasm on students' perceived enthusiasm.

'Effect of students' perceived enthusiasm on students' interest.

\section{! Indirect effect of dipositional teacher enthusiasm on students interest, mediated by students' perceived teacher enthusiasm.}

Brophy, J. E, \& Good, T. L. (1986). Teacher behavior and student achievement. In M. Wittrock (Ed.), Handbook of research on teaching (Vol. 3); (pp. 328 375). New York: Macmillan.

Collins, M. L. (1978). Effects of enthusiasm training on preservice elementary teachers. Journal of Teacher Education, 29, 5357.

Feldman, K. A. (2007). Identifying exemplary teachers and teaching: evidence from student ratings. In R. P. Perry, \& J. C. Smart (Eds.), The scholarship of teaching and learning in higher education An evidence-based perspective (pp. 93 143). Dordrecht: Springer.

Frenzel, A. C. Teacher emotions. In L. Linnenbrink-Garcia, \& R. Pekrun (Eds.), Handbook of emotions in education. New York: Routledge (in press).

Frenzel, A. C., Goetz, T., Lüdtke, O., Pekrun, R., \& Sutton, R. E. (2009). Emotional transmission in the classroom: exploring the relationship between teacher and student enjoyment. Journal of Educational Psychology, 101(3), 705 716. http:// dx.doi.org/10.1037/a0014695.

Goetz, T., Pekrun, R., Hall, N., \& Haag, L. (2006). Academic emotions from a socialcognitive perspective: antecedents and domain specificity of students' affect in the context of Latin instruction. British Journal of Educational Psychology, 76(2), 289 308. http://dx.doi.org/10.1348/000709905x42860.

Gross, J. J., \& John, O. P. (1997). Revealing feelings: facets of emotional expressivity in self-reports, peer ratings, and behavior. Journal of Personality and Social Psychology, 72(2), 435448. 
Gross, J. J., \& John, O. P. (1998). Mapping the domain of expressivity: multimethod evidence for a hierarchical model. Journal of Personality and Social Psychology, 74(1), 170 191. http://dx.doi.org/10.1037/0022-3514.74.1.170.

Gross, J. J., John, O. P., \& Richards, J. M. (2000). The dissociation of emotion expression from emotion experience: a personality perspective. Personality and Social Psychology Bulletin, 26(6), 712 726. http://dx.doi.org/10.1177/0146167200268006.

Hidi, S., \& Renninger, K. A. (2006). The four-phase model of interest development. Educational Psychologist, 41(2), 111 127. http://dx.doi.org/10.1207 s15326985ep4102_4.

Hu, L.-t., \& Bentler, P. M. (1999). Cutoff criteria for fit indexes in covariance structure analysis: conventional criteria versus new alternatives. Structural Equation Modeling: A Multidisciplinary Journal, 6(1), 1 55. http://dx.doi.org/10.1080/ 10705519909540118.

Keller, M. M., Neumann, K., \& Fischer, H. E. (2013). Teacher enthusiasm and student achievement. In J. Hattie, \& E. M. Andermann (Eds.), International guide to student achievement (pp. 247 250).

King, L. A \& Emmons, R. A. (1990). Conflict over emotional expression: psychological and physical correlates. Journal of Personality and Social Psychology, 58(5), 864 877. http://dx.doi.org/10.1037/0022-3514.58.5.864.

Krapp, A. (2007). An educational psychological conceptualisation of interest. International Journal for Educational and Vocational Guidance, 7, 5 21. http:// dx.doi.org/10.1007/s10775-007-9113-9.

Kring, A. M., Smith, D. A., \& Neale, J. M. (1994). Individual differences in dispositional expressiveness: development and validation of the Emotional Expressivity Scale. Journal of Personality and Social Psychology, 66(5), 934 949. http:/ dx.doi.org/10.1037/0022-3514.66.5.934.

Kunter, M., Frenzel, A. C., Nagy, G., Baumert, J., \& Pekrun, R. (2011). Teacher enthusiasm: dimensionality and context specificity. Contemporary Educational Psychology, 36, 289 301. http://dx.doi.org/10.1016/j.cedpsych.2011.07.001.

Kunter, M., Klusmann, U., Baumert, J., Richter, D., Voss, T., \& Hachfeld, A. (2013). Professional competence of teachers: effects on instructional quality and student development. Journal of Educational Psychology, 105(3), 805 820. http:// dx.doi.org/10.1037/a0032583.

Kunter, M., Tsai, Y.-M., Klusmann, U., Brunner, M., Krauss, S., \& Baumert, J. (2008). Students' and mathematics teachers' perceptions of teacher enthusiasm and instruction. Learning and Instruction, 18(5), 468 482. http://dx.doi.org/10.1016 j.learninstruc.2008.06.008.

Lüdtke, O., Trautwein, U., Kunter, M., \& Baumert, J. (2006). Reliability and agreement of student ratings in the classroom environment: a reanalysis of TIMSS data. Learning Environment Research, 9, 215 230. http://dx.doi.org/10.1007/s10984006-9014-8.

Maas, C. J. M., \& Hox, J. J. (2005). Sufficient sample sizes for multilevel modeling Methodology: European Journal of Research Methods for the Behavioral and Social Sciences, 1(3), 86 92. http://dx.doi.org/10.1027/1614-2241.1.3.86.

Marsh, H. W. (2007). Students' evaluations of university teaching: dimensionality, reliability, validity, potential biases and usefulness. In R. P. Perry, \& J. C. Smart (Eds.), The scholarship of teaching and learning in higher education (pp. 319 383). Dordrecht: Springer.
Marsh, H. W., \& Bailey, M. (1993). Multidimensional students' evaluations of teaching effectiveness: a profile analysis. The Journal of Higher Education, 64(1), 118.

Marsh, H. W., Lüdtke, O., Nagengast, B., Trautwein, U., Morin, A. J. S., Abduljabbar, A. S. et al. (2012). Classroom climate and contextual effects: conceptual and methodological issues in the evaluation of group-level effects. Educational Psychologist, 47(2), 106 124. http://dx.doi.org/10.1080/00461520.2012.670488.

Mohiyeddini, C., John, O., \& Gross, J. J. (2008). Der 'Berkeley Expressivity Questionnaire': Deutsche Adaption und erste Validierungsbefunde [German version of the Berkeley Expressivity Questionnaire]. Diagnostica, 54(3), 117 128. http:// dx.doi.org/10.1026/0012-1924.54.3.117.

Morris, J. A., \& Feldman, D. C. (1996). The dimensions, antecedents, and consequences of emotional labor. Academy of Management Review, 21(4), 9861010.

Murray, H. G. (1983). Low-inference classroom teaching behaviors and student ratings of college teaching effectiveness. Journal of Educational Psychology, 75(1), 138 149. http://dx.doi.org/10.1037/0022-0663.75.1.138.

Murray, H. G. (2007). Low-inference teaching behaviors and college teaching effectiveness: recent developments and controversies. In R. P. Perry, \& J. C. Smart (Eds.), The scholarship of teaching and learning in higher education (pp. 145 200). Dordrecht: Springer.

Muthén, B. O., \& Muthén, L. K. (1998 2012). Mplus user's guide (7th ed.). Los Angeles, CA: Muthén \& Muthén.

Nett, U. E., Goetz, T., \& Hall, N. (2011). Coping with boredom in school: an experience sampling perspective. Contemporary Educational Psychology, 36, 4959. http://dx.doi.org/10.1016/j.cedpsych.2010.10.003.

Parker, P. D., Marsh, H. W., Lüdtke, O., \& Trautwein, U. (2013). Differential school contextual effects for math and English: integrating the big-fish-little-pond effect and the internal/external frame of reference. Learning and Instruction, 23, 78 89. http://dx.doi.org/10.1016/j.learninstruc.2012.07.001.

Patrick, B. C., Hisley, J., \& Kempler, T. (2000). 'What's everybody so excited about?': the effects of teacher enthusiasm on student intrinsic motivation and vitality. Journal of Experimental Education, 68(3), 217 236. http://dx.doi.org/10.1080/ 00220970009600093.

Rosenberg, E., \& Ekman, P. (1994). Coherence between expressive and experiential systems in emotion. Cognition \& Emotion, 8(3), 201 229. http://dx.doi.org/ 10.1080/02699939408408938.

Rosenshine, B. (1970). Enthusiastic teaching: a research review. The School Review $78(4), 499514$

Stenlund, K. V. (1995). Teacher perceptions across cultures: the impact of students on teacher enthusiasm and discouragement in a cross-cultural context. Alberta Journal of Educational Research, 41(2), 145161.

Stevenson, A., \& Waite, M. (2011). Concise Oxford English Dictionary (12th ed.). New York: Oxford University Press.

Sutton, R. E., \& Wheatley, K. F. (2003). Teachers' emotions and teaching: a review of the literature and directions for future research. Educational Psychology Review, 15(4), 327 358. http://dx.doi.org/10.1023/A:1026131715856.

Ware, J. E., \& Williams, R. G. (1975). The Dr. Fox effect: a study of lecturer effectiveness and ratings of instruction. Journal of Medical Education, 50(2), 149156. 